\title{
Effect of Dental Environment Stressors and Coping Mechanisms on Perceived Stress in Postgraduate Dental Students
}

\author{
Neha Sikka ${ }^{1}$, Ruchi Juneja ${ }^{2}$, Varun Kumar ${ }^{3}$, Shashi Bala ${ }^{4}$
}

\begin{abstract}
Aim and objective: To investigate the effect of dental environment stressors and coping mechanisms on perceived stress in postgraduate dental students.

Materials and methods: This cross-sectional study enrolled 250 postgraduate students from four dental colleges. Modified dental environment stress (DES) questionnaire was used to study the dental environment-related stressors, perceived stress score (PSS) to measure the extent of stress perception, and brief COPE (BC) scale to measure the use of various coping strategies deployed to combat stress. An independent $T$-test was used to determine the associations of these measures with gender and marital status and one-way ANOVA for associations with year of study. Hierarchical regression was used to determine the effect of demographic factors, career-related psychological background, health-related habits, DES, and BC score on PSS.

Results: "Synopsis, thesis, library dissertation" and "lack of adequate infrastructure" were reported as the highest stressors by the postgraduate students. Only $4.8 \%$ of respondents perceived low stress, while $65.2 \%$ perceived high stress. A high correlation between the DES score and PSS was observed. Active coping, acceptance, and positive reframing were the most commonly utilized coping strategies. Planning and use of emotional support were the only coping strategies that were significant negative predictors of PSS. Problem-focused coping strategies had a positive, but non-significant correlation with PSS, while emotion-focused coping strategies had a significant negative correlation with PSS. Conclusion: Postgraduate dental environment causes a high-stress perception in students and reactive coping strategies have only a limited role in reducing stress perception.
\end{abstract}

Keywords: Coping, Dental, Perceived stress, Postgraduate students.

International Journal of Clinical Pediatric Dentistry (2021): 10.5005/jp-journals-10005-2005

\section{INTRODUCTION}

Stress pervades all professions. ${ }^{1}$ Although a moderate amount of stress arising out of deadlines, expectations, and competition acts as a stimulant, and drives one to perform to maximum capacity, overwhelming stress paralyzes the cognitive and behavioral capacities of the individual, affecting his wellbeing. ${ }^{2}$ On the work front, it negatively affects productivity ${ }^{3}$ and induces absenteeism; ${ }^{4}$ on the personal front, it breeds frustrations, spoils relationships, ${ }^{5}$ and causes one to resort to alcoholism, ${ }^{6}$ smoking, ${ }^{7}$ and drugs to evade the reality. ${ }^{8}$

Stress also adversely affects the academic performances of students. ${ }^{9}$ In medical institutes where academics, research, and patient care are integral parts of post-graduation curriculum, a daunting work routine, urgent need to upgrade knowledge and skills, deadlines for thesis submission, research work publication, with little time for relaxation and recreation create a highly vulnerable environment for stress, anxiety, and depression. ${ }^{10}$

Among all health professions, dental students are reported to be more prone to stress. ${ }^{11}$ Dentistry involves a technically demanding nature of work, requires thorough knowledge of involved biological sciences, and necessitates constant upgradation with upcoming advancements. Therefore, learning and excelling at it involves considerable hard work, mental faculties, emotional resilience, social support, and guidance.

Literature is replete with studies to elucidate the factors associated with an increase in stress in dental undergraduate students. ${ }^{12-20}$ Lack of time for leisure activity, neglect of personal life,

\footnotetext{
1,4 Department of Dental Materials, Post Graduate Institute of Dental Sciences, Rohtak, Haryana, India

${ }^{2,3}$ Department of Dentistry, Kalpana Chawla Government Medical College, Karnal, Haryana, India
}

Corresponding Author: Ruchi Juneja, Department of Dentistry, Kalpana Chawla Government Medical College, Karnal, Haryana, India, Phone: +91 9501172632, e-mail: ruchijuneja1986@gmail.com

How to cite this article: Sikka N, Juneja R, Kumar V, et al. Effect of Dental Environment Stressors and Coping Mechanisms on Perceived Stress in Postgraduate Dental Students. Int J Clin Pediatr Dent 2021;14(5): 681-688.

Source of support: Nil

Conflict of interest: None

examination anxiety, workload, patient expectations, and worries about future careers are the most commonly reported stressors for dental students. ${ }^{12-20}$

The extent of stress perception, however, depends not only on the environmental stressors but also on various other factors, including sociodemographic factors, personality traits, psychological background, emotional intelligence, occupation, ${ }^{21}$ and ability to utilize coping strategies. ${ }^{22}$ Stress perception by dental undergraduate students has also been studied by various researchers. ${ }^{23-30}$ However, the research work to study the prevalence of stress in postgraduate dental students, the factors perceived most stressful, and the extent of stress perception is 
relatively scarce. ${ }^{31,32}$ Similarly, a few studies have analyzed the effect of different types of coping strategies on stress perception by dental undergraduate students, ${ }^{33,34}$ but no similar research on postgraduate dental students could be found.

Owing to the scarcity of studies on stressors, differences in perception, and coping strategies in postgraduate dental students, this study was planned to study various factors causing stress, coping strategies deployed, and the effect of the interplay of these factors on perceived stress in postgraduate dental students.

The null hypotheses tested were: (1) There is no association between dental environment stress (DES) score and perceived stress score (PSS). (2) There is no association between brief COPE (BC) (coping orientation to problems experienced) score and PSS.

\section{Materials and Methods}

The research was conducted in accordance with ethical principles enshrined in the World Medical Association's Declaration of Helsinki and was approved by the Institutional Ethics Committee. The study was designed as a cross-sectional survey making use of a structured questionnaire to collect data from postgraduate students of four dental colleges of Haryana. With an $80 \%$ prevalence level of stress, $95 \%$ confidence level with standard normal distribution, and $5 \%$ margin of error, a sample size of 246 was considered sufficient. To compensate for the non-responsive participants, and incompletely/ incorrectly filled questionnaires, a total of 280 participants were included in the study.

"Stress analysis and coping questionnaire" used in this survey had sections of demographic and academic details, stress and psychological background, health behavior, DES, perceived stress, stress manifestations, and coping strategies. Care was taken to keep the questionnaire comprehensive to address all areas of interest while keeping it brief at the same time to enhance responsiveness. Demographic and academic factors included age, gender, marital status, dental specialty, and year of study. Stress and psychological background in the context of dental career were assessed based on whether the respondents were satisfied by their choice of the dental profession and post-graduation specialty or not. Health behavior was assessed by seven questions eliciting information on a routine of 8 hours of sleep, physical exercise habits, breakfast habits, snacking in-between meals, taking health supplements, alcohol, and tobacco consumption habits to be responded on a three-point scale of no, sometimes, and yes.

The DES component was a modified version of the DES questionnaire $^{35}$ adapted to include various factors pertinent to postgraduate learning environments, while keeping it concise. It included 35 questions to evaluate stressors -3 questions to determine self-efficacy beliefs, 7 questions to assess personal and accommodation factors, 8 questions to study curriculum associated factors, 9 questions relating to educational environment factors, and 8 questions to assess the role of various clinical factors using a four-point Likert scale.

Perceived stress scale was used to measure the degree to which situations were appraised as stressful. ${ }^{36}$ It included 10 questions to assess the respondents' subjective experiences of feelings during the previous month. Feelings included were: being upset, loss of control over life, nervousness, confidence to handle a problem, feeling of things going the right way, inability to cope with things, inability to control irritations, feeling on top of the world, anger, and feeling of piling up difficulties to the level difficult to overcome. Responses were obtained on a five-point Likert scale from never to very often.

Information on stress manifestations was obtained by general experiences of fatigue, eye strain, back pain, headache, sleep disturbances, stomach upsets, flu-like symptoms, oral ulcers, mood alterations, and affected performance.

Coping strategies were measured using the $B C$ questionnaire which is a multidimensional measure of cognitive and behavioral strategies used to regulate the behavior in response to stressors. ${ }^{37}$ It included 28 questions relating to stress coping strategies to be answered on a four-point Likert scale from "never" to "very often". Fourteen coping strategies were included in the questionnaire, i.e., self-distraction, active coping, denial, use of emotional support, behavioral disengagement, venting, use of instrumental support, positive reframing, self-blaming, planning, humor, acceptance, religion, and substance use.

After explaining the purpose of the study to the volunteers, obtaining written consent, and assuring them the confidentiality, the questionnaires were distributed. The participants were requested to return the filled sheets the same day.

Incompletely filled questionnaires were not included in statistical analysis. The data were analyzed using Microsoft excel 2007 and IBM SPSS statistics 19 (IBM Corp., New York, USA). Coding of the data was done for analytical purposes. Mean health behavior score was calculated by coding the responses of "no", "sometimes", and "yes" into 1, 2, and 3, respectively, for all factors except alcohol and tobacco consumption. For alcohol and tobacco consumption, the responses were reverse coded (no $=3$, sometimes $=2$, yes $=$ 1). The average of all health behavior responses was then taken as the "mean health behavior" score. For the DES score, the Likert responses of "not stressful" to "severely stressful" were coded 1 to 4 and the mean score for each item was calculated. For PSS, the Likert responses of "never" to "very often" were coded 0 to 4 for negatively stated items. Positively stated items were reverse-scored and finally summated to remaining items to achieve assessment score. Scores ranging from 0 to 13 were considered low stress, 14 to 26 were considered moderate, and 27 to 40 would be considered high perceived stress.

For the BC score, the coding for responses from "never" to "very often" were assigned as 1 to 4, and the mean was calculated for an individual item. Cronbach's alpha was used to assess the internal consistency of various tools of the questionnaire.

The primary outcome measures were the DES score, PSS, and BC score. Secondary outcome measures were the mean health score and manifestations of stress. Bivariate associations (e.g., based on gender and marital status) were tested for statistical significance using the independent $T$-test and Pearson's correlations. Variability between independent variable groups - the year of study and specialty of post-graduation-was assessed using univariate ANOVA. Correlations among DES, PSS, and BC were calculated using Pearson moment correlation. To identify the significant predictors of PSS, a hierarchical multiple regression model (method: Enter) was fitted to control the effect of sociodemographic, academic, and health-related factors. Age, gender, and marital status were entered in the first block; year of study, specialty, and career-related background in the second block; health behavior in the third block; and DES and BC in the final block. In general, a two-sided $p$ value $<0.05$ was considered significant. 


\section{Results}

Out of 280 questionnaires distributed, 263 were received back, and 250 were found to be complete and suitable for statistical evaluation. Cronbach's alpha coefficient for the questionnaire was 0.882 for the 35 -item DES questionnaire, 0.813 for the 10 -item perceived stress scale questionnaire, and 0.833 for the 28 -item BC inventory reflecting a good internal validity.

The demographic details of all the participants are shown in Table 1. The sample was a composite of nine dental specialties. Most of the participants were of the 26-30 age group and were unmarried. Only $38.4 \%$ of the participants had opted for dentistry as their career of the first choice. $81.6 \%$ of the participants got admission to the post-graduation specialty of their choice. A T-test revealed that both the DES score and the PSS were significantly higher in the students who did not opt for dentistry as the first

Table 1: Demographic description of the study population

\begin{tabular}{llc}
\hline Variables & & $N(\%)$ \\
\hline Gender & Male & $107(42.8)$ \\
& Female & $143(57.2)$ \\
& Year 1 & $79(31.6)$ \\
& Year 2 & $87(34.8)$ \\
& Year 3 & $84(33.6)$ \\
Marital status (years) & $<25$ & $61(24.4)$ \\
& $26-30$ & $170(68.0)$ \\
Specialty & $31-35$ & $16(6.4)$ \\
& $36-40$ & $3(1.2)$ \\
& Single & $172(68.8)$ \\
& Orthodontics & $78(31.2)$ \\
& Prosthodontics & $31(12.4)$ \\
& Oral Medicine and Radiology & $30(12.0)$ \\
& Conservative Dentistry and & $24(9.6)$ \\
& Endodontics & $25(10.0)$ \\
& Pedodontics & $30(12)$ \\
& Periodontics & $27(10.8)$ \\
& Oral Pathology & $29(11.6)$ \\
& Preventive and Community Dentistry & $26(10.4)$ \\
& Oral and Maxillofacial Surgery & $28(11.2)$ \\
\hline
\end{tabular}

career of choice. The DES scores were higher in students who did not get their specialty of choice in post-graduation.

Our assessment of health behavior revealed that only $14 \%$ of the respondents had a habit of regular exercise, and only $35.2 \%$ had an average 8 -hour sleep. $20.8 \%$ of the respondents skipped breakfast daily; $14.8 \%$ consumed alcohol routinely, and $64.4 \%$ consumed occasionally; $9.6 \%$ used tobacco routinely and $84.8 \%$ occasionally; and snacking in-between meals was routine for $35.6 \%$ of respondents. There was a significant gender difference in physical exercise behavior-more males engaged in physical exercises $(p=0.000)$. The habit of alcohol and tobacco consumption also showed gender predilection - these were significantly more in males ( $p=0.001$ ). Daily breakfast habit was significantly higher in married students when compared with unmarried ones $(p=0.018)$. Tobacco consumption was significantly higher in unmarried students $(p=0.019)$. Taking health supplements had a weak but significant negative correlation with both DES and PSS ( $p=0.016$ and 0.023 , respectively). Routine alcohol drinkers had significantly more PSS than occasional drinkers $(p=0.005)$. However, the overall mean health behavior score had no significant correlation with DES, PSS, or BC score ( $p=0.809,0.596$, and 0.348 , respectively).

Table 2 presents the DES score for the five DES domains, and the comparison of DES scores for gender, year of study, and marital status. Overall, synopsis, thesis and library dissertation, and lack of adequate infrastructure were reported as the most stressful factors. Although the gender, the year of study, and the marital status did not influence the overall DES score significantly, self-efficacy beliefs and personal and accommodation factors caused significantly more stress in females than males (Table 2). Unmarried students also had significantly higher stress due to self-efficacy beliefs when compared with married students. Among specializations, postgraduate students in prosthodontics had significantly higher DES scores than other specialties $(p=0.002)$.

Stress was perceived most commonly as a feeling of nervousness or anger. $4.8 \%$ of respondents perceived low stress, $30 \%$ perceived moderate stress, while $65.2 \%$ perceived high stress. PSS comparison for the year of the study showed significantly higher stress perception in first-year students as compared to second-and third-year students. Gender, marital status, and post-graduation specialty did not affect PSS significantly (Table 3).

Only $3.2 \%$ of the respondents reported no stress manifestations. Fatigue was the most common manifestation of stress followed by back pain, mood alteration, and headache. Significantly more

Table 2: Comparison of mean dental environment stress (DES) score for various domains between genders, years of study, and marital status

\begin{tabular}{|c|c|c|c|c|c|c|c|c|}
\hline & \multirow[b]{2}{*}{ Mean (SD) } & \multicolumn{2}{|c|}{ Gender } & \multicolumn{3}{|c|}{ Year of study } & \multicolumn{2}{|c|}{ Marital status } \\
\hline & & Male & Female & I & II & III & Unmarried & Married \\
\hline Self-efficacy beliefs & $7.71(2.28)$ & $7.19(1.89)$ & $8.09(2.46)^{* *}$ & $7.77(2.22)$ & $7.91(1.97)$ & $7.46(2.59)$ & $7.98(2.24)^{* *}$ & $7.12(2.28)$ \\
\hline $\begin{array}{l}\text { Personal and accom- } \\
\text { modation factors }\end{array}$ & $16.28(4.39)$ & $15.59(4.16)$ & $16.7(4.50)^{*}$ & $16.73(4.23)$ & $16.31(4.24)$ & $15.84(4.68)$ & $16.14(4.37)$ & $16.59(4.45)$ \\
\hline $\begin{array}{l}\text { Curriculum } \\
\text { associated factors }\end{array}$ & $18.83(4.23)$ & $19.32(4.29)$ & $18.47(4.16)$ & $18.87(5.03)$ & $18.67(3.46)$ & $18.95(4.16)$ & $18.92(4.14)$ & $18.63(4.45)$ \\
\hline $\begin{array}{l}\text { Education } \\
\text { environment factors }\end{array}$ & $20.59(5.32)$ & $20.81(4.49)$ & $20.42(5.87)$ & $20.09(6.37)$ & $20.20(3.67)$ & $21.43(5.56)$ & $20.95(5.63)$ & $19.81(4.49)$ \\
\hline Clinical factors & 19.09 (5.06) & 18.39 (4.67) & $19.62(5.29)$ & $18.86(4.52)$ & $18.93(4.88)$ & $19.46(5.69)$ & 19.34 (4.99) & $18.54(5.19)$ \\
\hline Total & $82.50(15.14)$ & $81.31(14.02)$ & $83.39(15.92)$ & $82.33(17.56)$ & $82.01(10.90)$ & 83.14 (16.39) & $83.33(15.46)$ & $80.68(14.34)$ \\
\hline
\end{tabular}

SD standard deviation, ${ }^{*} p<0.05,{ }^{* *} p<0.005$ 
females experienced mood alterations $(p=0.000)$ and reported that their performance was being affected ( $p=0.022$ ). Males reported headache as the second most common stress manifestation. Mood alterations were significantly higher in third-year students when compared with both first- and second-year students $(p=0.002)$, and in married students when compared with unmarried ones ( $p$ $=0.054$ ). Sleep disturbances and flu occurrences were significantly more in unmarried students ( $p=0.004$ and 0.001 , respectively).

The most common coping strategy utilized by the students was active coping-efforts and actions to make the situation better, followed by accepting the situation and learning to live with it. Positive reframing strategy - to see the situation in a positive light was third in the order. While significantly more male participants looked for something good in what is happening, they also engaged more in self-criticism and alcohol consumption. On the other hand, significantly more females tried to accept the situation and learn to live with it. Whereas significantly more unmarried candidates turned to work, married candidates, on the other hand, gave up the attempt to cope (Table 4).

Table 3: Comparison of mean perceived stress score (PSS) between genders, years of study, and marital status

\begin{tabular}{lll}
\hline Variable & Mean (SD) & Significance ( $p$ value) \\
\hline Gender & & \\
Male & $20.81(4.65)$ & 0.586 \\
$\quad$ Female & $21.14(4.72)$ & \\
Year of study & & \\
$\quad$ First year & $21.68(5.25)^{*}$ & 0.017 \\
Second year & $19.82(3.92)$ & \\
Third year & $21.52(4.66)^{*}$ & \\
Marital status & \\
Unmarried & $21.06(4.92)$ & 0.749 \\
Married & 20.86 & \\
Total & $21.00(4.69)$ & \\
\hline
\end{tabular}

$\mathrm{SD}$, standard deviation, ${ }^{*} p<0.05$
Dental environment stress, PSS, and BC were found to be strongly correlated in all the domains ( $p=0.000$ for all domains). Results of hierarchical regression analysis revealed that two components of DES - self-efficacy beliefs and personal and accommodation factors-were significant positive predictors of PSS (Table 5). Hence, the null hypothesis that "there is no association between dental environment stress (DES) score and perceived stress score (PSS)" was rejected. Regression analysis for BC inventorybased coping strategies revealed that the use of emotional support and planning were significant negative predictors of PSS, while self-blaming, humor, and acceptance were significant positive predictors of PSS (Table 5). Analysis for approach-based categorization of coping revealed that problem-focused coping strategies were negative predictors of PSS, although the association was weak and non-significant (Table 6). Emotion-focused coping strategies, on the other hand, were significant positive predictors of PSS (Table 6). Hence, the null hypothesis that "there is no association between BC score and PSS" also stands rejected.

The data that support the findings of this study are available from the corresponding author upon request.

\section{Discussion}

Stress has generally been considered as a product of an imbalance between external demands and individual capacities. ${ }^{38}$ This "product of imbalance" has been known to produce a state of burnout in dental students, in turn adversely affecting mental and physical wellbeing. ${ }^{14}$ Therefore, it becomes critical to study the stressors responsible and the extent of perception of the stress by the postgraduate students.

Results of this study showed a very high level of stress perception by postgraduate students in the dental college environment. We observed that only $38.4 \%$ of the participants had opted for dentistry as their career of the first choice. In India, admission to an undergraduate course in dentistry is not through a separate entrance examination, but it is through a common entrance test for medical and dental courses, which tends to make the dental

Table 4: Comparison of mean brief COPE (BC) score for various coping strategies between genders, years of study, and marital status

\begin{tabular}{|c|c|c|c|c|c|c|c|c|}
\hline & \multirow[b]{2}{*}{ Mean (SD) } & \multicolumn{2}{|c|}{ Gender } & \multicolumn{3}{|c|}{ Year of study } & \multicolumn{2}{|c|}{ Marital status } \\
\hline & & Male & Female & I & II & III & Unmarried & Married \\
\hline Self-distraction & $4.65(1.54)$ & $4.53(1.51)$ & $4.73(1.55)$ & $4.35(1.37)$ & $4.83(1.68)$ & $4.74(1.51)$ & $4.84(1.53)^{* *}$ & $4.23(1.48)$ \\
\hline Active coping & $5.23(1.69)$ & $5.03(1.75)$ & $5.38(1.64)$ & $5.38(1.55)$ & $5.56(1.80)$ & $4.74(1.63)^{*}$ & $5.19(1.58)$ & $5.32(1.92)$ \\
\hline Denial & $3.76(1.66)$ & $3.77(1.52)$ & $3.75(1.75)$ & $3.69(1.38)$ & $3.76(1.77)$ & $3.82(1.78)$ & $3.73(1.64)$ & $3.83(1.69)$ \\
\hline $\begin{array}{l}\text { Use of emotional } \\
\text { support }\end{array}$ & $4.59(1.58)$ & $4.40(1.60)$ & $4.73(1.55)$ & $4.35(1.24)$ & $4.40(1.62)$ & $5.01(1.75)^{*}$ & $4.62(1.62)$ & $4.52(1.49)$ \\
\hline $\begin{array}{l}\text { Behavioral } \\
\text { disengagement }\end{array}$ & $4.01(1.68)$ & $4.07(1.59)$ & $3.96(1.75)$ & $3.93(1.60)$ & $3.80(1.77)$ & $4.29(1.65)$ & $3.79(1.66)$ & $4.50(1.64)^{* *}$ \\
\hline Venting & $3.99(1.26)$ & $3.97(1.17)$ & $4.01(1.32)$ & $4.10(1.19)$ & $3.91(1.27)$ & $3.98(1.32)$ & $3.93(1.26)$ & $4.14(1.27)$ \\
\hline $\begin{array}{l}\text { Use of instrumental } \\
\text { support }\end{array}$ & $4.87(1.46)$ & $4.75(1.47)$ & $4.96(1.44)$ & $4.77(1.47)$ & $4.94(1.54)$ & $4.88(1.36)$ & $4.93(1.50)$ & $4.73(1.35)$ \\
\hline Positive reframing & $5.00(1.63)$ & $5.03(1.66)^{*}$ & $4.98(1.60)$ & $5.23(1.72)$ & $5.14(1.75)$ & $4.64(1.33)$ & $4.98(1.67)$ & $5.05(1.52)$ \\
\hline Self-blaming & $4.49(1.44)$ & $4.75(1.51)^{*}$ & $4.29(1.35)$ & $4.24(1.35)$ & $4.51(1.56)$ & 4.69 (1.38) & $4.50(1.59)$ & $4.46(1.05)$ \\
\hline Planning & $4.86(1.67)$ & $4.78(1.72)$ & $4.92(1.63)$ & $4.79(1.56)$ & $5.10(1.79)$ & $4.68(1.60)$ & $4.80(1.58)$ & $5.00(1.85)$ \\
\hline Humor & $4.87(1.84)$ & $4.73(1.89)$ & $4.98(1.80)$ & $4.63(1.95)$ & $5.32(1.87)^{*}$ & $4.63(1.63)$ & $4.92(1.85)$ & $4.75(1.84)$ \\
\hline Acceptance & $5.06(1.66)$ & $4.71(1.49)$ & $5.32(1.74)^{* *}$ & $5.15(1.79)$ & $5.29(1.63)$ & $4.74(1.54)$ & $5.09(1.67)$ & $4.97(1.65)$ \\
\hline Religion & $4.59(1.84)$ & $4.42(1.97)$ & $4.71(1.73)$ & $4.52(1.69)$ & $4.80(1.88)$ & $4.43(1.92)$ & $4.61(1.80)$ & 4.54 (1.92) \\
\hline Substance use & $2.41(0.87)$ & $2.77(1.11)^{* * *}$ & $2.14(0.49)$ & $2.38(0.82)$ & $2.23(0.73)$ & $2.62(1.02)^{*}$ & $2.42(0.86)$ & $2.39(0.92)$ \\
\hline
\end{tabular}

SD, standard deviation, ${ }^{*} p<0.05,{ }^{* *} p<0.005,{ }^{* * *} p<0.001$ 
Stress in Postgraduate Dental Students

Table 5: Multiple (hierarchical) regression model for PSS predicted by various study factors (method: enter)

\begin{tabular}{|c|c|c|c|c|c|c|c|}
\hline Model & Variables & $B(95 \% C l)$ & $S E B$ & $\beta$ & $p$ & $R^{2}$ change & F model test \\
\hline \multirow[t]{3}{*}{1} & Age & $-0.233(-0.527,0.060)$ & 0.149 & -0.123 & 0.119 & 0.011 & 0.951 \\
\hline & Gender & $-0.024(-01.284,1.237)$ & 0.640 & -0.002 & 0.971 & & \\
\hline & Marital status & $0.431(-1.063,1.926)$ & 0.759 & 0.043 & 0.570 & & \\
\hline \multirow[t]{6}{*}{2} & Age & $-0.196(-0.494,0.101)$ & 0.151 & -0.104 & 0.195 & 0.026 & 0.149 \\
\hline & Gender & $-0.042(-1.307,1.222)$ & 0.642 & -0.004 & 0.947 & & \\
\hline & Marital status & $0.896(-0.659,2.4520)$ & 0.790 & 0.089 & 0.258 & & \\
\hline & Dental specialty & $0.043(-0.198,0.284)$ & 0.122 & 0.022 & 0.726 & & \\
\hline & Year of post-graduation & $-0.968(-1.739,-0.197)$ & 0.391 & -0.167 & 0.014 & & \\
\hline & Career-related psychological background & $0.503(-0.420,1.425)$ & 0.468 & 0.073 & 0.284 & & \\
\hline \multirow[t]{7}{*}{3} & Age & $-0.206(-0.506,0.093)$ & 0.152 & -0.109 & 0.176 & 0.002 & 0.188 \\
\hline & Gender & $-0.009(-1.278,1.260)$ & 0.644 & -0.001 & 0.989 & & \\
\hline & Marital status & $0.905(-0.653,2.462)$ & 0.791 & 0.090 & 0.254 & & \\
\hline & Dental specialty & $0.050(-0.192,0.292)$ & 0.123 & 0.026 & 0.684 & & \\
\hline & Year of post-graduation & $-0.964(-1.736,-0.192)$ & 0.392 & -0.166 & 0.015 & & \\
\hline & Career-related psychological background & $0.508(-0.415,1.432)$ & 0.469 & 0.074 & 0.279 & & \\
\hline & Mean health score & $-0.100(-0.366,0.166)$ & 0.135 & -0.047 & 0.460 & & \\
\hline \multirow[t]{28}{*}{4} & Age & $-0.035(-0.288,0.218)$ & 0.128 & -0.018 & 0.787 & $0.425^{*}$ & $0.000^{*}$ \\
\hline & Gender & $-0.705(-1.886,0.477)$ & 0.600 & -0.075 & 0.241 & & \\
\hline & Marital status & $0.672(-0.610,1.955)$ & 0.651 & 0.067 & 0.303 & & \\
\hline & Dental specialty & $-0.076(-0.289,0.137)$ & 0.108 & -0.040 & 0.481 & & \\
\hline & Year of post-graduation & $-0.881(-1.570,-0.191)$ & 0.350 & -0.152 & 0.013 & & \\
\hline & Career-related psychological background & $0.364(-0.423,1.151)$ & 0.399 & 0.053 & 0.363 & & \\
\hline & Mean health score & $-0.001(-0.221,0.220)$ & 0.112 & 0.000 & 0.996 & & \\
\hline & DES & & & & & & \\
\hline & Self-efficacy beliefs & $0.348(0.056,0.639)$ & 0.148 & 0.169 & 0.020 & & \\
\hline & Personal and accommodation factors & $0.240(0.076,0.405)$ & 0.084 & 0.225 & 0.004 & & \\
\hline & Curriculum factors & $-0.015(-0.196,0.166)$ & 0.092 & -0.013 & 0.872 & & \\
\hline & Education environment factors & $0.014(-0.118,0.145)$ & 0.067 & 0.015 & 0.838 & & \\
\hline & Clinical factors & $0.113(-0.013,0.238)$ & 0.064 & 0.122 & 0.078 & & \\
\hline & $\mathrm{BC}$ & & & & & & \\
\hline & Self-distraction & $-0.055(-0.469,0.359)$ & 0.210 & -0.018 & 0.793 & & \\
\hline & Active coping & $0.112(-0.250,0.474)$ & 0.184 & 0.040 & 0.542 & & \\
\hline & Denial & $0.008(-0.341,0.358)$ & 0.177 & 0.003 & 0.963 & & \\
\hline & Use of emotional support & $-0.650(-1.011,-0.289)$ & 0.183 & -0.219 & 0.000 & & \\
\hline & Behavioral disengagement & $0.250(-0.116,0.617)$ & 0.186 & 0.090 & 0.180 & & \\
\hline & Venting & $0.063(-0.408,0.534)$ & 0.239 & 0.017 & 0.794 & & \\
\hline & Use of instrumental support & $-0.083(-0.541,0.375)$ & 0.232 & -0.026 & 0.721 & & \\
\hline & Positive reframing & $0.094(-0.304,0.491)$ & 0.202 & 0.032 & 0.643 & & \\
\hline & Self-blaming & $0.596(0.218,0.974)$ & 0.192 & 0.184 & 0.002 & & \\
\hline & Planning & $-0.629(-1.051,-0.208)$ & 0.214 & -0.224 & 0.004 & & \\
\hline & Humor & $0.813(0.457,1.168)$ & 0.180 & 0.320 & 0.000 & & \\
\hline & Acceptance & $0.089(-0.308,0.486)$ & 0.201 & 0.032 & 0.660 & & \\
\hline & Religion & $0.465(0.165,0.765)$ & 0.152 & 0.182 & 0.002 & & \\
\hline & Substance use & $-0.514(-1.149,0.121)$ & 0.322 & -0.096 & 0.112 & & \\
\hline
\end{tabular}

$\mathrm{B}$, regression coefficient; $\mathrm{Cl}$, confidence interval; $\mathrm{SE}$, standard error; $\beta$, standard estimate; $p$, significance; ${ }^{*} p<0.001$

course a second choice for the aspirants. It was also interesting to note that the students who could not get the specialty of choice in post-graduation had significantly higher DES. It is plausible that those students had a low opinion of their current branch and its future scope, which in turn could have affected the score.
It was observed that only $14 \%$ of participants had a habit of regular physical exercise, and as high as $79.2 \%$ of participants consumed alcohol routinely or occasionally. Lack of physical activity was significantly associated with increased DES score in the present study. Physical activity has, for a long, been reported to decrease 
Stress in Postgraduate Dental Students

Table 6: Comparison of mean scores of various coping categories between genders and results of multiple regression for PSS predicted by coping categories after control of demographic factors, academic factors, mean health score, and DES by use of Hierarchical method

\begin{tabular}{|c|c|c|c|c|c|c|c|c|}
\hline & \multicolumn{4}{|c|}{ Independent T-test } & \multicolumn{4}{|c|}{ Regression analysis } \\
\hline & Total Mean (SD) & Male Mean (SD) & Female Mean (SD) & $p$ value & $B$ & $S E B$ & $\beta$ & $p$ \\
\hline Maladaptive coping & $23.31(4.83)$ & $23.87(5.37)$ & $22.89(4.36)$ & 0.126 & 0.073 & 0.069 & 0.076 & 0.291 \\
\hline Adaptive coping & $39.07(7.82)$ & $37.85(7.22)$ & $39.99(8.13)^{* *}$ & 0.032 & 0.061 & 0.040 & 0.102 & 0.128 \\
\hline Problem-focused coping & $14.96(3.73)$ & $14.56(3.52)$ & $15.26(3.86)$ & 0.190 & -0.187 & 0.097 & -0.149 & 0.055 \\
\hline Emotion-focused coping & $47.42(7.94)$ & $47.16(8.49)$ & $47.62(7.53)$ & 0.554 & 0.169 & 0.048 & 0.286 & $0.000^{* * *}$ \\
\hline
\end{tabular}

SD, standard deviation; B, regression coefficient; SE, standard error; $\beta$, Standard estimate; $p$, significance; ${ }^{* *} p<8.13 ;{ }^{* * *} p<0.001$

depression, ${ }^{39}$ and anxiety. ${ }^{40}$ However, the experience of stress has also been reported to have a negative impact on physical exercise. ${ }^{41}$

Routine alcohol drinkers had significantly more stress than occasional drinkers $(p=0.005)$. As bi-directional relationships have been reported between alcohol consumption and stress, ${ }^{42}$ whether alcohol consumption caused increased stress or consumption increased because of DES cannot be commented for sure.

"Submission of Synopsis, thesis and Library Dissertation" and "lack of adequate infrastructure" were identified as the most stressful dental environment factors. This is partly in agreement with Divaris et al. ${ }^{31}$ who also reported seminar presentations and inadequate staff in clinics among the top five stressors in dental postgraduates, with lack of leisure time being at the top. Interestingly, among the factors included in the DES questionnaire, competition from other postgraduate students was the least stressful factor in our study.

Factors related to self-efficacy beliefs were identified as significantly more stressful by females and married respondents. Overall stress score was higher for females than males. An explanation for higher reported stress in female students may lie in greater expressivity of thoughts and feelings, particularly the negative ones by them. ${ }^{43}$

Prosthetic dentistry was identified as the most stressful dental specialty both in terms of DES as well as PSS, as Divaris et al. ${ }^{31}$ also reported. It may be attributed to prolonged working hours due to excessive laboratory work, patient satisfaction challenges, and the absence of proper laboratory facilities in colleges leading to the requirement of more coordination between private laboratories and patients. Oral medicine and radiology was identified as the least stressful branch.

Whereas the DES score was not significantly influenced by the year of study, PSS was highest among the first-year students, followed closely by third-year students. This may be explained by the fact that whereas first-year students face challenges in terms of new people, place, and environment apart from a sudden increase in workload, third-year students have additional stressors in the form of examinations, thesis submission, publication, and future career.

The stress response after a critical event is often modified by the supportive coping processes facilitated by physiological or behavioral mechanisms. Though coping does not directly reduce stress levels, it moderates the impact of stress. ${ }^{44} \mathrm{~A}$ significant positive correlation between BC score and PSS in this study suggests that whereas overwhelming stress led the students to the deployment of coping strategies to the best of their capabilities, it could not result in the corresponding reduction of PSS. In the present study, adaptive strategies, i.e., active coping, acceptance, and positive reframing were utilized much more than maladaptive coping strategies like substance abuse, denial, and venting. Similar to numerous studies in non-medical academic environments, problem-focused coping strategies were more effective than emotion-focused coping strategies. ${ }^{44-46}$ Another point to note is that the COPE score used in this study measures only reactive coping strategies. ${ }^{47}$ It has been reported that proactive coping strategies-ones which are utilized before stress appears-are associated with less stress while reactive coping strategies are associated with more stress.

A limitation of this study is the use of a closed-ended questionnaire to ease coding and statistical analysis of the responses, leading to a possible exclusion of certain potential stressors not mentioned in the questionnaire. Furthermore, stress and psychological background were considered only in the context of dental career while other background factors existing before admission in dental college, or individual personality-related stress factors were not considered. Additionally, perceived stress scale used in this study is a tool of temporal nature, which may be influenced by day-to-day problems and the recruitment of new coping strategies. Relatively small sample size and information bias due to the self-reported nature of data are other limitations of the present study.

This study highlights the need to address the mental health issues of postgraduate students in dental colleges. Efforts should be directed toward resolving infrastructure and equipment issues, thesis and dissertation jitters, and curriculum concerns of postgraduate students. Equally important are efforts directed to enhance the resilience by providing a supporting ecosystem to them lest the resulting burnout erodes all the motivation, severely affecting wellbeing.

\section{ConCLUSION}

We found that increased stress due to the dental environment correlated with increased perception of stress by the students. We also observed that the reactive coping strategies deployed by the students to deal with the effects of increased stress had limited efficacy in reducing the stress perception.

\section{ACKNOWLedgments}

We sincerely acknowledge all the participants of this study.

\section{References}

1. Johnson S, Cooper C, Cartwright S, et al. The experience of workrelated stress across occupations. J Manag Psychol 2005;20(2):178187. DOI: $10.1108 / 02683940510579803$.

2. Henderson RK, Snyder HR, Gupta T, et al. When does stress help or harm? The effects of stress controllability and subjective stress 
response on stroop performance. Front Psychol 2012;3:179. DOI: 10.3389/fpsyg.2012.00179.

3. Street TD, Lacey SJ, Somoray K. Employee stress, reduced productivity, and interest in a workplace health program: a case study from the Australian mining industry. Int J Environ Res Public Health 2018;16(1):94. DOI: 10.3390/ijerph16010094.

4. Heo YS, Leem JH, Park SG, et al. Job stress as a risk factor for absences among manual workers: a 12-month follow-up study. Ind Health 2015;53(6):542-552. DOI: 10.2486/indhealth.2015-0021.

5. Buck AA, Neff LA. Stress spillover in early marriage: the role of selfregulatory depletion. J FamPsychol 2012;26(5):698-708. DOI: 10.1037/ a0029260.

6. Siegrist J, Rödel A. Work stress and health risk behavior. Scand J Work Environ Health 2006;32(6):473-481. DOI: 10.5271/sjweh.1052.

7. Ng DM, Jeffery RW. Relationships between perceived stress and health behaviors in a sample of working adults. Health Psychol 2003;22(6):638-642. DOI: 10.1037/0278-6133.22.6.638.

8. Sinha R. Chronic stress, drug use, and vulnerability to addiction. Ann N Y Acad Sci 2008;1141(1):105-130. DOI: 10.1196/annals.1441.030.

9. Crego A, Carrillo-Diaz M, Armfield JM, et al. Stress and academic performance in dental students: the role of coping strategies and examination-related self-efficacy. J Dent Educ 2016;80(2):165-172. DOI: 10.1002/j.0022-0337.2016.80.2.tb06072.x.

10. Kumar B, Shah MAA, Kumari R, et al. Depression, anxiety, and stress among final-year medical students. Cureus 2019;11(3):e4257. DOI: 10.7759/cureus.4257.

11. Birks Y, McKendree J, Watt I. Emotional intelligence and perceived stress in healthcare students: a multi-institutional, multi-professional survey. BMC Med Educ 2009;9(1):61. DOI: 10.1186/1472-6920-9-61.

12. Al-Saleh SA, Al-Madi EM, Al-Angari NS, et al. Survey of perceived stress-inducing problems among dental students, Saudi Arabia. Saudi Dent J 2010;22(2):83-88. DOI: 10.1016/j.sdentj.2010.02.007.

13. Elani HW, Bedos C, Allison PJ. Sources of stress in Canadian dental students: a prospective mixed methods study. J Dent Educ 2013;77(11):1488-1497. DOI: 10.1002/j.0022-0337.2013.77.11.tb05625.x.

14. PöhImann $K$, Jonas I, Ruf $S$, et al. Stress, burnout and health in the clinical period of dental education. Eur J Dent Educ 2005;9(2):78-84. DOI: 10.1111/j.1600-0579.2004.00359.x.

15. Jowkar Z, Masoumi M, Mahmoodian H. Psychological stress and stressors among clinical dental students at shiraz school of dentistry, Iran. Adv Med Educ Pract 2020;11:113-120.

16. Gorter R, Freeman R, Hammen S, et al. Psychological stress and health in undergraduate dental students: fifth year outcomes compared with first year baseline results from five European dental schools. Eur J Dent Educ 2008;12(2):61-68. DOI: 10.1111/j.1600-0579.2008.00468.x.

17. Tangade PS, Mathur A, Gupta R, et al. Assessment of stress level among dental school students: an Indian outlook. Dent Res J (Isfahan) 2011;8(2):95-101.

18. Naidu RS, Adams JS, Simeon D, et al. Sources of stress and psychological disturbance among dental students in the West Indies. J Dent Educ 2002;66(9):1021-1030. DOI: 10.1002/j.00220337.2002.66.9.tb03569.x.

19. Abu-Ghazaleh SB, Sonbol HN, Rajab LD. A longitudinal study of psychological stress among undergraduate dental students at the University of Jordan. BMC Med Educ 2016;16(1):90. DOI: 10.1186/ s12909-016-0612-6.

20. Harikiran AG, Srinagesh J, Nagesh KS, et al. Perceived sources of stress amongst final year dental under graduate students in a dental teaching institution at Bangalore, India: a cross sectional study. Indian J Dent Res 2012;23(3):331-336. DOI: 10.4103/0970-9290.102218.

21. Vallejo MA, Vallejo-Slocker L, Fernández-Abascal EG, et al. Determining factors for stress perception assessed with the perceived stress scale (PSS-4) in Spanish and other European samples. Front Psychol 2018;9:37. DOI: 10.3389/fpsyg.2018.00037.

22. Enns A, Eldridge GD, Montgomery C, et al. Perceived stress, coping strategies, and emotional intelligence: a cross-sectional study of university students in helping disciplines. Nurse Educ Today 2018;68:226-231. DOI: 10.1016/j.nedt.2018.06.012.
23. Basudan S, Binanzan N, Alhassan A. Depression, anxiety and stress in dental students. Int J Med Educ 2017;8:179-186. DOI: 10.5116/ ijme.5910.b961.

24. Jiménez-Ortiz JL, Islas-Valle RM, Jiménez-Ortiz JD, et al. Emotional exhaustion, burnout, and perceived stress in dental students. J Int Med Res 2019;47(9):4251-4259. DOI: 10.1177/0300060519859145.

25. Ersan N, Fişekçioğlu E, Dölekoğlu S, et al. Perceived sources and levels of stress, general self-efficacy and coping strategies in clinical dental students. Psychol Health Med 2017;22(10):1175-1185. DOI: 10.1080/13548506.2017.1286359.

26. Kumar S, Dagli RJ, Mathur A, et al. Perceived sources of stress amongst Indian dental students. Eur J Dent Educ 2009;13(1):39-45. DOI: 10.1111/j.1600-0579.2008.00535.x.

27. Saddki N, Sukerman N, Mohamad D. Association between emotional intelligence and perceived stress in undergraduate dental students. Malays J Med Sci 2017;24(1):59-68. DOI: 10.21315/mjms2017.24.1.7.

28. Veeraboina N, Doshi D, Kulkarni S, et al. Perceived stress and coping strategies among undergraduate dental students - an institutional based study. Int J Adolesc Med Health 2020(0). DOI: /j/ijamh.aheadof-print/ijamh-2019-0070/ijamh-2019-0070.xml. doi:10.1515/ijamh2019-0070.

29. Silverstein ST, Kritz-Silverstein D. A longitudinal study of stress in first-year dental students. J Dent Educ 2010;74(8):836-848. DOI: 10.1002/j.0022-0337.2010.74.8.tb04940.x.

30. Nguyen TTT, Seki N, Morio I. Stress predictors in two Asian dental schools with an integrated curriculum and traditional curriculum. Eur J Dent Educ 2018;22(3):e594-e601. DOI: 10.1111/eje.12358.

31. Divaris K, Polychronopoulou A, Taoufik K, et al. Stress and burnout in postgraduate dental education. Eur J Dent Educ 2012;16(1):35-42. DOI: 10.1111/j.1600-0579.2011.00715.x.

32. Ghafoor S, Chaudhry S, Khan JS. Marital status as a stress indicator in postgraduate dental students. J Pak Med Assoc 2020;70(1):158-161. DOI: 10.5455/JPMA.4571.

33. Al-Sowygh ZH. Academic distress, perceived stress and coping strategies among dental students in Saudi Arabia. Saudi Dent J 2013;25(3):97-105. DOI: 10.1016/j.sdentj.2013.05.002.

34. Alzahem AM, Van der Molen HT, Alaujan AH, et al. Stress management in dental students: a systematic review. Adv Med Educ Pract 2014;5:167-176. DOI: 10.2147/AMEP.S46211.

35. Garbee WH, Zucker SB, Selby GR. Perceived sources of stress among dental students. J Am Dent Assoc 1980;100(6):853-857. DOI: 10.14219/ jada.archive.1980.0279.

36. Cohen S, Kamarck T, Mermelstein R. A global measure of perceived stress. J Health Soc Behav 1983;24(4):385-396. DOI: 10.2307/ 2136404

37. Carver CS. You want to measure coping but your protocol's too long: consider the brief COPE. Int J Behav Med 1997;4(1):92-100. DOI: 10.1207/s15327558ijbm0401_6.

38. Lazarus RS, Folkman S. Stress, appraisal, and coping. New York: Springer; 1984.

39. Rethorst CD, Wipfli BM, Landers DM. The antidepressive effects of exercise: a meta-analysis of randomized trials. Sports Med 2009;39(6):491-511. DOI: 10.2165/00007256-200939060-00004.

40. Wipfli BM, Rethorst CD, Landers DM. The anxiolytic effects of exercise: a meta-analysis of randomized trials and dose-response analysis. J Sport Exerc Psychol 2008;30(4):392-410. DOI: 10.1123/ jsep.30.4.392.

41. Lutz RS, Stults-Kolehmainen MA, Bartholomew JB. Exercise caution when stressed: stages of change and the stress-exercise participation relationship. Psychol Sport Exerc 2010;11(6):560-567. DOI: 10.1016/j. psychsport.2010.06.005.

42. Childs $\mathrm{E}, \mathrm{O}^{\prime}$ Connor $\mathrm{S}$, de Wit $\mathrm{H}$. Bidirectional interactions between acute psychosocial stress and acute intravenous alcohol in healthy men. Alcohol Clin Exp Res 2011;35(10):1794-1803. DOI: 10.1111/j.15300277.2011.01522.x.

43. Deng $Y$, Chang $L$, Yang $M$, et al. Gender differences in emotional response: inconsistency between experience and expressivity. PLoS One 2016;11(6):e0158666. DOI: 10.1371/journal.pone.0158666. 
44. Lazarus RS. Coping theory and research: past, present, and future. Psychosom Med 1993;55(3):234-247. DOI: 10.1097/00006842199305000-00002.

45. Nahlén C, Saboonchi F. Coping, sense of coherence and the dimensions of affect in patients with chronic heart failure. Eur J Cardiovasc Nurs 2010;9(2):118-125. DOI: 10.1016/j.ejcnurse.2009.11.006.
46. Galiana L, Tomás JM, Fernández I, et al. Predicting well-being among the elderly: the role of coping strategies. Front Psychol 2020;11:616. DOI: 10.3389/fpsyg.2020.00616.

47. Moring J, Fuhrman R, Zauszniewski JA. Interrelatedness of proactive coping, reactive coping, and learned resourcefulness. Meas Eval Couns Dev 2011;44(4):204-214. DOI: 10.1177/0748175611414722. 